\title{
International Society of Preventive Oncology
}

National Cancer Institute

\section{Source}

National Cancer Institute. International Society of Preventive Oncology. NCI Thesaurus. Code $C 39433$.

The International Society of Preventive Oncology (ISPO) is the forum of an international membership committed to the study of interactive etiologic factors in cancer development and their impact on prevention, detection, and management of neoplastic diseases. Publishes CDP (Cancer Detection and Prevention) Journal. 